\title{
Quantitative proteomic analysis of the influence of lignin on biofuel production by Clostridium acetobutylicum ATCC 824
}

\author{
Mahendra P. Raut ${ }^{1}$, Narciso Couto ${ }^{1}$, Trong K. Pham ${ }^{1}$, Caroline Evans ${ }^{1}$, Josselin Noirel ${ }^{1,2}$ and Phillip C. Wright ${ }^{1,3^{*}}$
}

\begin{abstract}
Background: Clostridium acetobutylicum has been a focus of research because of its ability to produce high-value compounds that can be used as biofuels. Lignocellulose is a promising feedstock, but the lignin-cellulose-hemicellulose biomass complex requires chemical pre-treatment to yield fermentable saccharides, including cellulose-derived cellobiose, prior to bioproduction of acetone-butanol-ethanol (ABE) and hydrogen. Fermentation capability is limited by lignin and thus process optimization requires knowledge of lignin inhibition. The effects of lignin on cellular metabolism were evaluated for C. acetobutylicum grown on medium containing either cellobiose only or cellobiose plus lignin. Microscopy, gas chromatography and 8-plex iTRAQ-based quantitative proteomic technologies were applied to interrogate the effect of lignin on cellular morphology, fermentation and the proteome.

Results: Our results demonstrate that C. acetobutylicum has reduced performance for solvent production when lignin is present in the medium. Medium supplemented with $1 \mathrm{~g} \mathrm{~L}^{-1}$ of lignin led to delay and decreased solvents production (ethanol; $0.47 \mathrm{~g} \mathrm{~L}^{-1}$ for cellobiose and $0.27 \mathrm{~g} \mathrm{~L}^{-1}$ for cellobiose plus lignin and butanol; $0.13 \mathrm{~g} \mathrm{~L}^{-1}$ for cellobiose and $0.04 \mathrm{~g} \mathrm{~L}^{-1}$ for cellobiose plus lignin) at 20 and $48 \mathrm{~h}$, respectively, resulting in the accumulation of acetic acid and butyric acid. Of 583 identified proteins (FDR $<1 \%$ ), 328 proteins were quantified with at least two unique peptides. Up- or down-regulation of protein expression was determined by comparison of exponential and stationary phases of cellobiose in the presence and absence of lignin. Of relevance, glycolysis and fermentative pathways were mostly down-regulated, during exponential and stationary growth phases in presence of lignin. Moreover, proteins involved in DNA repair, transcription/translation and GTP/ATP-dependent activities were also significantly affected and these changes were associated with altered cell morphology.

Conclusions: This is the first comprehensive analysis of the cellular responses of $C$. acetobutylicum to lignin at metabolic and physiological levels. These data will enable targeted metabolic engineering strategies to optimize biofuel production from biomass by overcoming limitations imposed by the presence of lignin.
\end{abstract}

Keywords: Clostridium acetobutylicum, Cellobiose, Lignin, Fermentative end products, Biofuel production, Quantitative proteomics, iTRAQ, Metabolic changes

\section{Background}

Due to growing uncertainties regarding the supply and cost of fuel transportation and concerns about their related environmental impact, the sustainable production of clean energy has become a strategic priority.

\footnotetext{
*Correspondence: phillip.wright@newcastle.ac.uk

${ }^{1}$ The ChELSI Institute, Department of Chemical and Biological

Engineering, University of Sheffield, Mappin Street, Sheffield S1 3JD, UK

Full list of author information is available at the end of the article
}

Lignocellulosic biomass has great potential as a prime feedstock for future biofuel generation, since it is promising source of mixed sugars for fermentative biofuels and chemical production thereby ensuring renewable and sustainable source of energy and also reducing environmental impacts [1]. For that reason, anaerobic Clostridia have received much attention in recent years because of their ability to produce alternative biofuels from renewable biomass and agricultural waste materials [2]. In 
particular, Clostridium acetobutylicum ATCC 824 (C. acetobutylicum) is a promising candidate. Although it is unable to utilize biopolymers (cellulose and hemicellulose) directly, [3] it can ferment wide range of biomass saccharides (such as cellobiose) into acetone-butanolethanol (ABE) [2] products and hydrogen $\left(\mathrm{H}_{2}\right)$ [4] once brought into solution (hydrolysate) by pre-treatment. Since the presence of lignin [forming 20-30 \% of lignocellulosic (wood) biomass] is a key challenge in biological/enzymatic hydrolysis of lignocellulose, $[5,6]$ various chemical pre-treatments are widely employed to obtained biomass hydrolysates (pre-treatment liquor).

However, major bottlenecks still hamper the economics of $\mathrm{ABE}$ production from biomass hydrolysate; in particular the production of lignin and its derivatives during chemical pre-treatments which have inhibitory effects on Clostridium on biofuel production [7]. The phenolic compounds from lignin degradation have been demonstrated as the main inhibitor of ABE fermentation by Clostridia [2, 8]. Alkali treatments at high temperature and pressure have been shown to be most effective technique for biomass pre-treatment to release fermentable sugars and most of the dissolved native lignins into the pre-treatment liquor [9]. Understanding the effects of lignin alone on Clostridium biology, with particular focus on $\mathrm{ABE}$ production, is key to mimic such hydrolysates and process optimization to target improved yield.

This study combines an analysis of the effect of lignin on cellobiose consumption, growth rate, morphology, $\mathrm{ABE}$ production with a quantitative proteomic analysis to measure alterations in proteins associated with the lignin bottleneck'. A soluble form of Kraft lignin, i.e. alkali lignin (carboxylated), was selected since previous studies into microbial degradation of lignin and bioconversion to value-added products have used Kraft lignins [10-15]. Since, metabolism in C. acetobutylicum is biphasic, with acidogenesis (acetic acid, butyric acid and $\mathrm{H}_{2}$ ) dominant during the exponential phase and solventogenesis (ABE) dominant during stationary phase [16], the proteome was relatively compared at specific time points (exponential and stationary phases) during growth on either cellobiose or cellobiose supplemented with lignin. This study employed 8-plex isobaric tags for relative and absolute quantitation (iTRAQ) to quantitatively profile biological replicates of the four sample types. Data were integrated with gas chromatographic (GC) analysis of $\mathrm{ABE}$ and $\mathrm{H}_{2}$ production.

\section{Results and discussion}

Carbohydrate polymers (cellulose and hemicellulose) and aromatic polymers (lignin) are the major components of lignocellulosic biomass that, upon hydrolysis (alkali/acid or enzymatic), produces fermentable sugars (that can be utilized by $C$. acetobutylicum) and non-fermentable phenol compounds. Therefore, it is very important to understand how the presence of lignin affects fermentation end products (ABE) formation and core metabolic pathways. This study focused on metabolic and physiological changes in C. acetobutylicum during growth on cellobiose only (hereafter: $\mathrm{C}$ condition) and cellobiose plus lignin (hereafter: CL condition) supplemented conditions. The workflow shown in Fig. 1 demonstrates the integrated metabolic and proteomics analysis.

\section{Effect of lignin on the cell morphology, growth and fermentative end products}

Microscopic observations showed filamentous morphology of $C$. acetobutylicum with asymmetric and phenotypic cell division when lignin was present in combination with cellobiose (Fig. $2 \mathrm{~d}-\mathrm{f}$ ) relative to cellobiose alone (Fig. $2 \mathrm{a}-\mathrm{c}$ ) in both exponential and stationary phases. The morphological changes suggest that the presence of lignin challenged the bacterial metabolism but did not affect the growth (based on dry cell biomass as shown in Fig. 3a), since similar growth trends were observed until the late exponential phase $(16 \mathrm{~h})$ for both $\mathrm{C}$ and CL. Upon reaching stationary phase, a significant reduction in cell biomass was observed in $\mathrm{C}$ compared to $\mathrm{CL}$ at $36 \mathrm{~h}$ (Fig. 3a). Alteration in cell morphology is a visible indicator of bacterial adaptation strategies to tackle different environmental stress conditions [17]. Reduction in cell biomass concentration in the $\mathrm{C}$ condition could reflect reduced cell size and sporulation during the stationary phase (Fig. 2a, b versus Fig. 2d, e) as previously proposed by Steiner et al. [18]. A comparatively faster rate of cellobiose consumption was observed in $C$ media compared to CL media in the exponential phase (Fig. 2a), consistent with lignin inhibition.

Metabolites production was also validated: acetic acid and butyric acid and hydrogen $\left(\mathrm{H}_{2}\right)$; acetone, ethanol and butanol were detected and quantified by GC, to measure acidogenesis and solventogenesis, respectively. Metabolite profiles between $\mathrm{C}$ and $\mathrm{CL}$ are shown in Fig. 3b-f (Additional file 1: Metabolites data). Metabolite production was significantly affected by the presence of lignin. The major change was lignin inhibition of butanol production in both exponential and stationary phases (Fig. 3f). Ethanol production was inhibited by lignin during exponential phase, but not stationary phase (Fig. 3e). Acetone production was below the level of detection for both $\mathrm{C}$ and $\mathrm{CL}$ conditions. In terms of acidogenesis, hydrogen production was statistically significantly lower in the $C L$ versus the $C$ condition throughout the experiment (Fig. 3b). The onset of acetic acid production began as soon as cells started to grow $(8 \mathrm{~h})$ and reached a maximum at $36 \mathrm{~h}$ (Fig. 3c), which was followed by butyric acid 


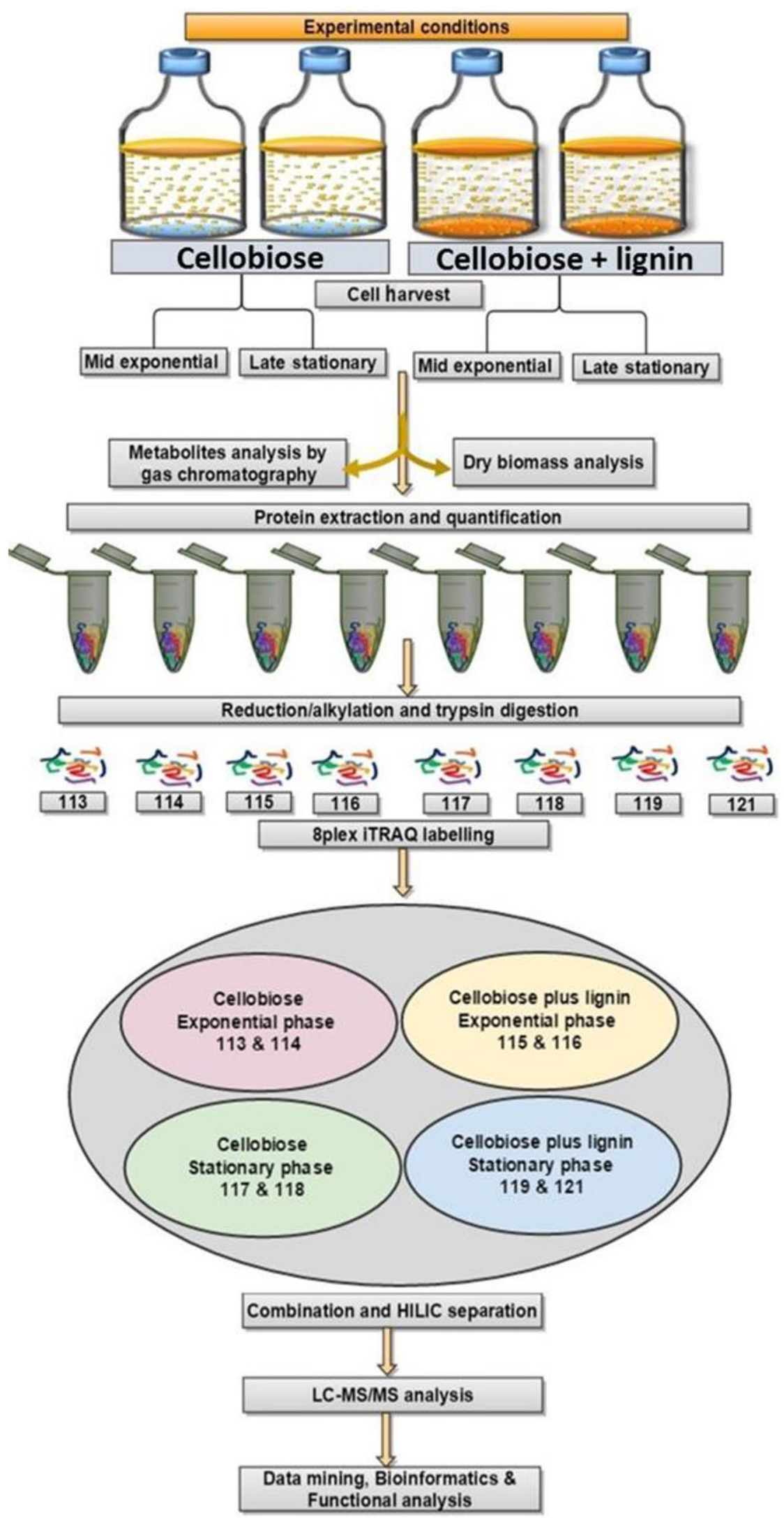


(See figure on previous page.)

Fig. 1 8-plex iTRAQ proteomic workflow. Proteins from eight individual samples (4 each for C and CL 2, exponential and 2 stationary phases) were digested into peptides that were tagged with isobaric stable isotope-labelled reagents. Relative quantification information was extracted upon collision-induced dissociation. 8-plex iTRAQ reagents tags have eight unique reporter ions of specific mass-to-charge $(\mathrm{m} / \mathrm{z})$ values $(113,114$, $115,116,117,118,119$ and 121) that produced peptide fragmentation during tandem MS and are used for relative quantitation by relative peak intensity. Fragmented peptide ions were used for peptide ID and protein identification. Samples for hydrogen, metabolites and dry cell biomass measures were taken in parallel

production, starting at $12 \mathrm{~h}$ and reaching a maximum at $36 \mathrm{~h}$ (Fig. 3d). Afterwards, a statistically significant decrease in acetic acid and butyric acid concentrations ( $p$ values of 0.018 and 0.01 , respectively) in $C$ versus $C L$ was observed that can be correlated with the statistically significantly higher ethanol and butanol production ( $p$ values of 0.006 and 0.0021 , respectively) in the $\mathrm{C}$ condition versus CL (ethanol; $0.47 \mathrm{~g} \mathrm{~L}^{-1}$ for $\mathrm{C}$ and $0.27 \mathrm{~g} \mathrm{~L}^{-1}$ for $\mathrm{CL}$ and butanol; $0.13 \mathrm{~g} \mathrm{~L}^{-1}$ for $\mathrm{C}$ and $0.04 \mathrm{~g} \mathrm{~L}^{-1}$ for $\mathrm{CL}$ ) (Fig. 3e, f). This indicates a rapid production of solvents in $C$ versus $C L$ and the accumulation of acids in the presence of lignin. Furthermore, there was delayed production of solvents in the presence of lignin, i.e. the onset of ethanol production started at 10 and $12 \mathrm{~h}$ for $\mathrm{C}$ and $\mathrm{CL}$
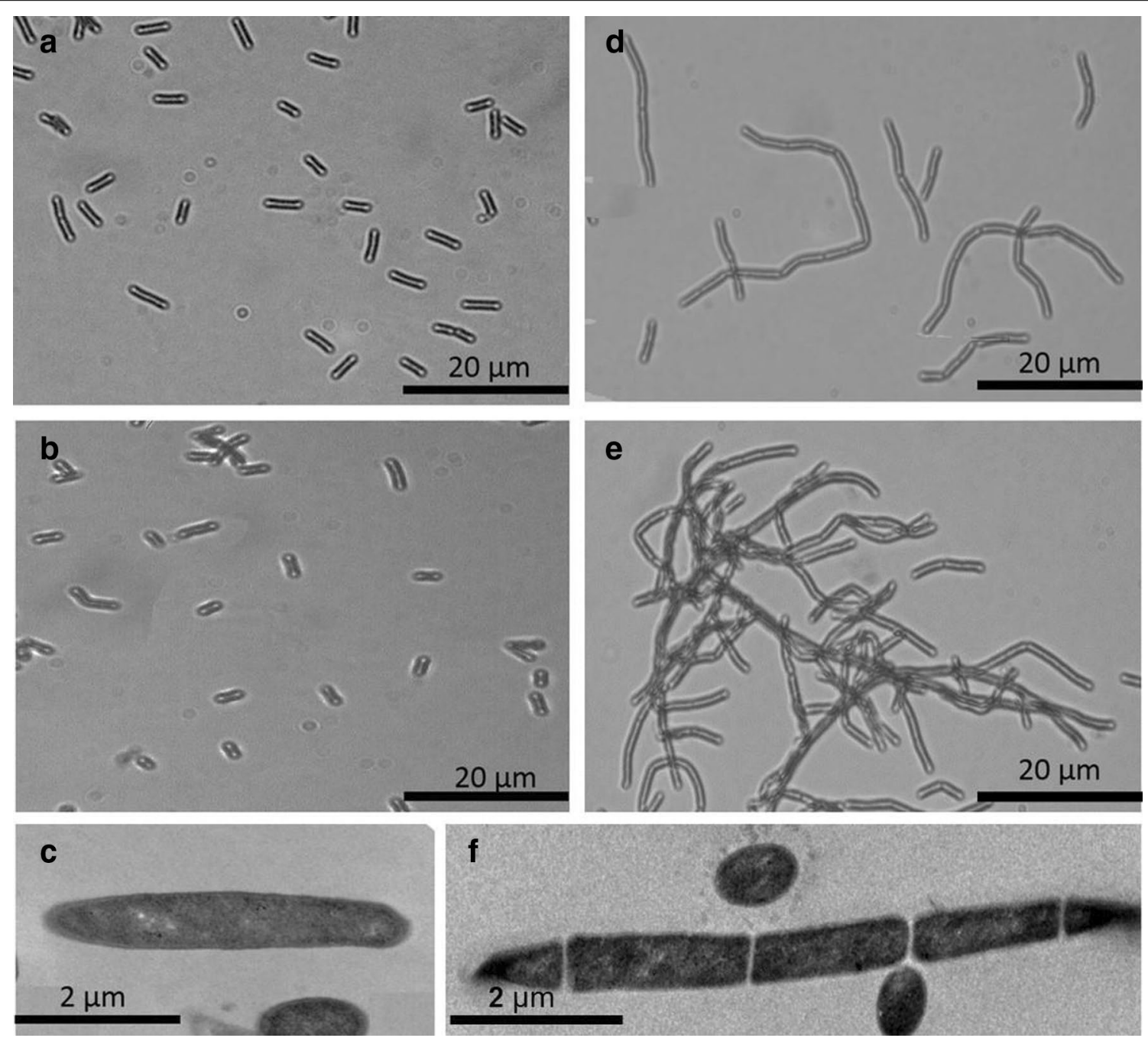

Fig. 2 Morphology of C. acetobutylicum cells grown on C (a-c) and CL (d-f) at exponential phase (16 h) as shown in a and $\mathbf{d}$ and stationary phase $(48 \mathrm{~h})$ as shown in $\mathbf{b}$ and $\mathbf{e}$. a-d were obtained by Olympus BX51 microscopy at $\times 60$ magnification and $\mathbf{c}$ and $\mathbf{e}$ were obtained by transmission electron microscopy (TEM) at $\times 11,000$ magnification 

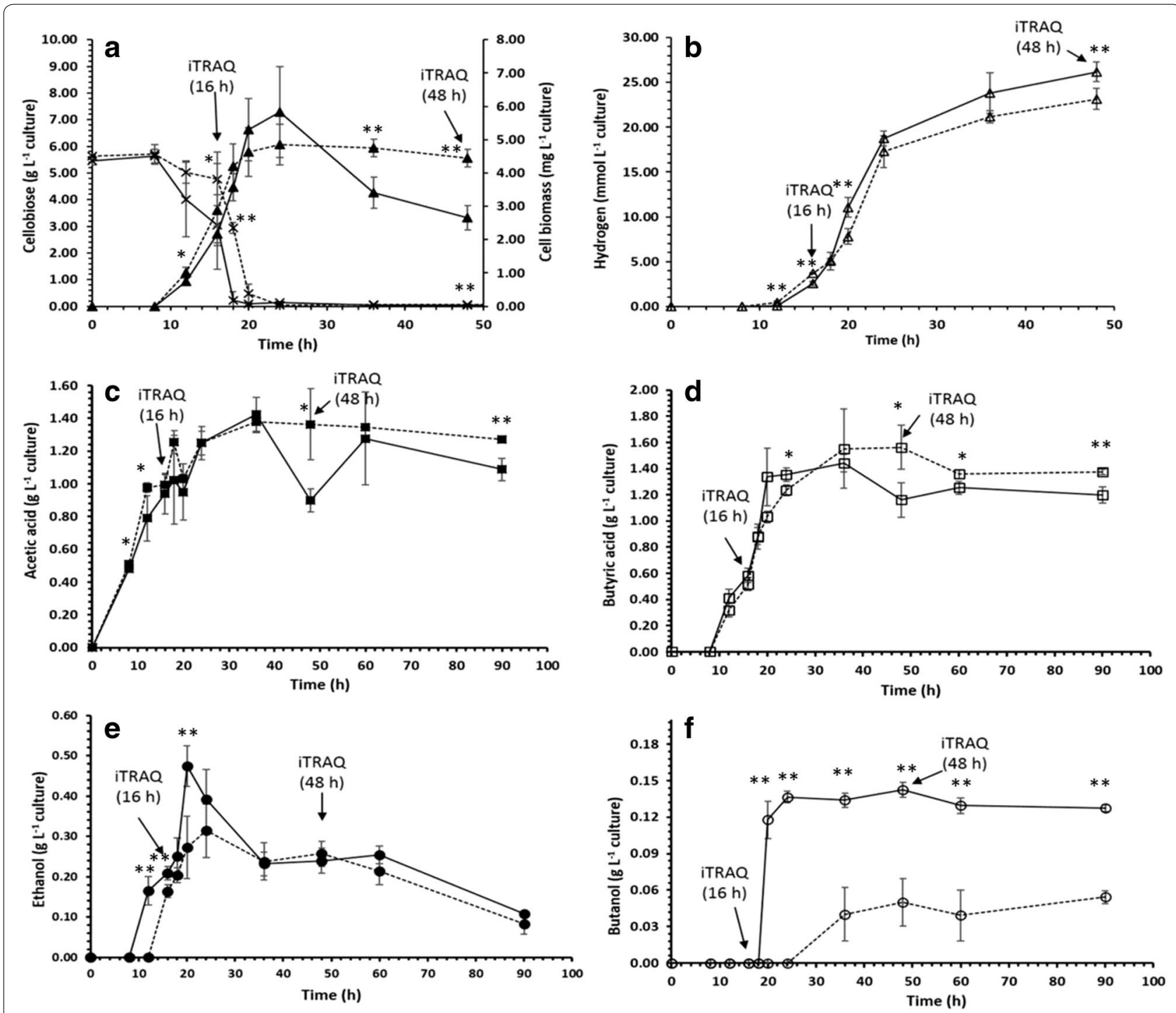

Fig. 3 Growth, cellobiose consumption and metabolite formation during fermentation in C. acetobutylicum under CL (dashed line) and C (solid line) conditions; a Growth/dry cell biomass (closed triangle), cellobiose consumption profiles (striked cross), $\mathbf{b} \mathrm{H}_{2}$ production (open triangle), c acetic acid (closed square), $\mathbf{d}$ butyric acid (open square) and e ethanol (closed circle) and $\mathbf{f}$ butanol (open circle). Data were taken from four biological replicates and mean values with the error bars indicate standard error of the mean. Arrows indicate the sampling points for iTRAQ quantitative proteomic analysis (16 and $48 \mathrm{~h}){ }^{*} p \leq 0.05$ and ${ }^{* *} p \leq 0.0099$

conditions and comparatively late butanol production started at 18 and $36 \mathrm{~h}$ for $\mathrm{C}$ and $\mathrm{CL}$ conditions, respectively. This is interesting that morphological changes (observed during transition of exponential to stationary) and reduced cell dry biomass concentration occur in $\mathrm{C}$ versus CL (Figs. 2, 3a).

In general, it is presumed that acid production and solvent production occur at different stages, but our results suggest that simultaneous acid and solvent production is occurring (metabolic shift) [19] during growth. Our results have some agreement though, with previous studies that show simultaneous production of acids and solvents during growth and suggest that acidogenic and solventogenic cells co-exist in the culture $[2,19]$.

Overall, the presence of lignin in the growth medium resulted in less $\mathrm{H}_{2}$ and solvent production (Fig. 3b, e, f). Usually, higher $\mathrm{H}_{2}$ production occurs when acetic acid and butyric acid are produced during the acidogenic growth phase (exponential phase), $[4,20]$ and it is believed to be due to accumulation of organic acids as a function of $\mathrm{pH}$ [21]. Acetic acid, butyric acid and $\mathrm{H}_{2}$ were reasonably high and concomitantly produced in both 
treatment conditions, which is in agreement with previous findings that a mixture of acetic acid and butyric acid as a fermentative product yields more $\mathrm{H}_{2}$ [22]. However, production seemed to be continued through the mid-stationary phase, indicating simultaneous acid and solvent production is possible, as previously observed [20].

Interestingly, acetone production was not observed. The results are consistent with previous observations in $C$. acetobutylicum when grown on cellobiose as the main carbon source, where higher $\mathrm{H}_{2}$, ethanol and acetic acid were produced as the main by-products and little or no acetone and butanol production was observed [23-25]. This study demonstrates substrate specificity and substrate-dependent fermentation flexibility of this bacterium.

Despite the versatility of $C$. acetobutylicum in producing acids, $\mathrm{H}_{2}$ and $\mathrm{ABE}$, very little is known about the dynamic regulation of metabolic networks, stoichiometry and directionality of metabolic fluxes in this bacterium [26]. It is believed that the efficiency of substrate conversion to final product solely depends on the direction of carbon intermediates and electron flow in the fermentation pathway [27, 28]. Therefore, since lignin had a negative effect on growth, morphology and fermentative products of $C$. acetobutylicum, we investigated this further by iTRAQ-based proteomics to gain insight into differential regulation of key proteins in the presence of lignin by comparing the exponential and stationary phases of cells grown under $\mathrm{C}$ and $\mathrm{CL}$ conditions.
Effect of lignin on C. acetobutylicum metabolism: an iTRAQ-based quantitative proteomic approach

A biological duplicate of each exponential and stationary phase from $C$ and $C L$ was chemically labelled using 8-plex iTRAQ reagents (following tryptic digestion to generate peptides) and analysed by HPLC-MS/MS analysis. Of 583 identified proteins (FDR $<1 \%$ ), 328 proteins were quantified with at least two unique peptides [29] (Additional file 2: Proteomic data). To evaluate replicates, hierarchical clustering (dendrogram) and principal component analysis (PCA) were applied to the iTRAQ reporter ion intensities. Hierarchical clustering (dendrogram form) and PCA analyses revealed that there was a clear clustering and distinction between biological replicates. Moreover, the proteomes of $\mathrm{C}$ and $\mathrm{CL}$ grown cells in their respective exponential and stationary phases were clustered closely in the same size of the dendrogram and PCA (Fig. 4) indicating similarity between replicates and differences between biological conditions. Notably, the proteome in all four comparisons (each of exponential and stationary phase of C and CL condition) was evidently different as shown in Fig. 4.

The effects of various lignin derivative compounds, metabolites and substrates stresses on Clostridia have been recently reviewed by Baral and Shah [7]. In particular, in C. acetobutylicum, several transcriptomics studies were dissected to study phase-related metabolism [30], physiological changes [31] and butanol stress or tolerance [32], but very few studies have been performed at the quantitative proteomics level. In a rare example, an

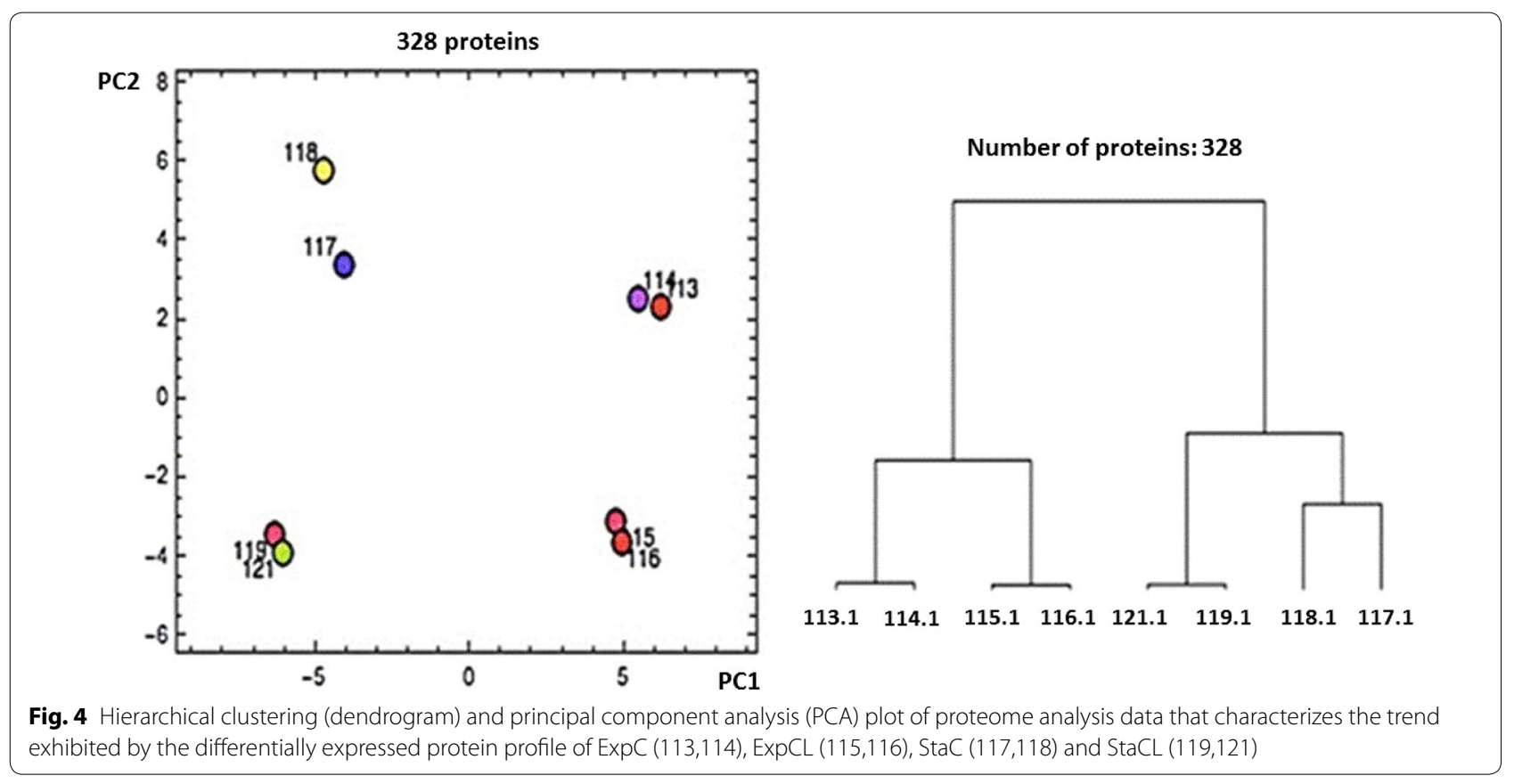


adaptive stress response of $C$. acetobutylicum to the toxic metabolites, butyrate and butanol, was recently analysed by Vekantraman et al. [33] using iTRAQ-based quantitative proteomics.

Our proteomics data provide vital information on differential expressions of proteins, thus providing a more detailed understanding of the effect of lignin on various cellular functions in C. acetobutylicum. A total 158 and 134 proteins were found to be differentially regulated in the exponential phase and stationary phases of CL, respectively, when compared to the exponential and stationary phases of cells grown in C media (ExpCL/ExpC and $\mathrm{StaCL} / \mathrm{StaC}$ ). Moreover, changes in protein expressions were also observed when shifting from exponential to stationary phase occurring in their respective conditions. In total, 173 and 216 proteins were differentially expressed in $\mathrm{C}(\mathrm{StaC} / \mathrm{ExpC})$ and $\mathrm{CL}$ (StaCL/ExpCL) conditions, respectively. These significantly differentially expressed proteins were mapped into pathways and the results are summarized in Figs. 5, 6 and 7. Lignin significantly changed the cellular functions of C. acetobutylicum, namely sugar transport, glycolysis, fermentative pathways, DNA replication, transcription/translation, cell division, sporulation/stress response and cell signalling/secretion. Therefore, these pathways/enzymes are discussed and correlated individually in the following sections.

\section{Protein expression changes associated with cellobiose transport and glycolysis regulation}

Our iTRAQ proteomics results revealed that proteins involved in the cellobiose transport system and glycolytic pathway were altered in expression levels by the presence of lignin. The majority of enzymes in these pathways were down-regulated in both exponential and stationary phase in the presence of lignin relative to the cellobioseonly condition.

Clostridium acetobutylicum can utilize a wide variety of carbohydrate sugars as carbon source and has multiple adaptable sugar transport and metabolic processes that are specifically regulated at the transcriptional level depending on environmental stress and nutrient conditions [34]. The phosphoenolpyruvate (PEP)-linked phosphotransferase system (PTS) is the major sugar transportation system exhibited in C. acetobutylicum. The PTS-dependent sugar transport systems are shown in Fig. 5. Usually, C. acetobutylicum uses a cellobiosespecific PTS system for cellobiose phosphorylation and transportation. The system consists of four proteins: PTS IIA (CA_C0383), PTS IIB (CA_C0384) and PTS IIC (CA C0386), and $\beta$ glucosidase (CA_C0385). In this study, the cellobiose-specific PTS complex was down-regulated in the presence of lignin (ExpCL/ExpC). However, the data suggest that to maintain the sugar level, cells adaptively switched to the non-specific mannose PTS system. The

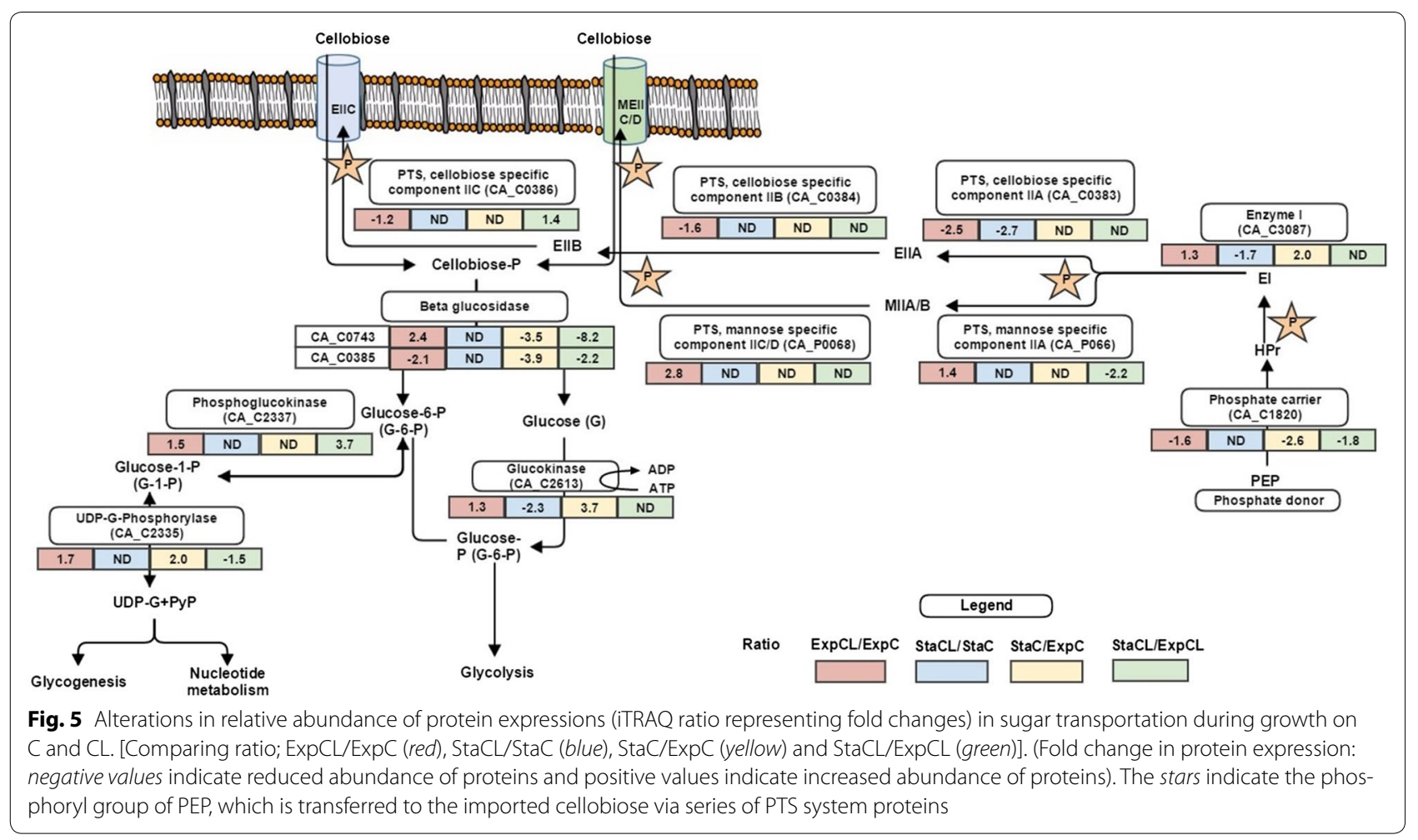




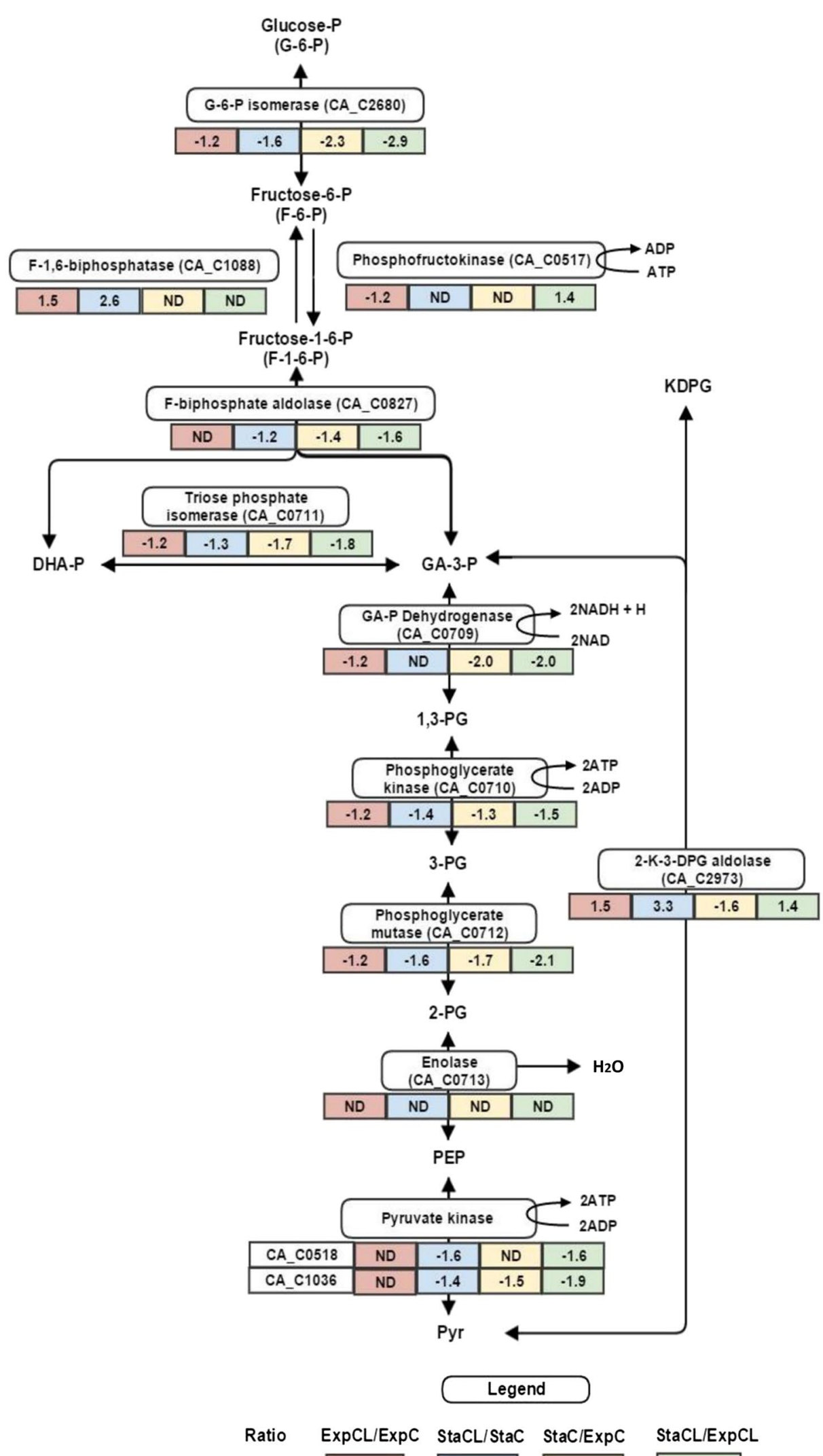


(see figure on previous page.)

Fig. 6 Alterations in relative abundance of protein expressions (iTRAQ ratio representing fold changes) in glycolysis during growth on C and $\mathrm{CL}$. [Comparing ratio; ExpCL/ExpC (red), StaCL/StaC (blue), StaC/ExpC (yellow) and StaCL/ExpCL (green)] (Fold change in protein expression: negative values indicate reduced abundance of proteins and positive values indicate increased abundance of proteins)

components of the non-specific mannose PTS system are IIA (CA_P0066), IIC/D (CA_P0068) and 6- $\beta$-glucosidase (CA_C0743) (possibly associated with mannose PTS system). These were found to be up-regulated (ExpCL/ ExpC). The data show that $C$. acetobutylicum possesses multiple cellobiose transport systems, as suggested by Servinesky et al. [34]. Thus, adaptive activation of different transport systems in different environmental stress conditions could be possible and reflected at the level of the proteome, which represents a novel finding.

The cellobiose/mannose PTS systems allow cellobiose to enter the cell, so that it can be further cleaved into glucose and glucose 6-P by $\beta$-glucosidases and enter the glycolytic pathway. Non-phosphorylated glucose molecules are further phosphorylated by glucokinase (CA_C2613) to glucose-6-P; a protein was found to be in increased abundance in CL (ExpCL/ExpC). Glucose6-P then enters into glycolysis (Fig. 6). In C. acetobutylicum, glucose to pyruvate conversion generally occurs via the Embden-Meyerhof-Parnas (EMP) pathway; the majority of measured proteins of the EMP pathway were down-regulated in the presence of lignin in the exponential phase. Since the metabolism of sugar presumably takes place during the exponential phase of $C$. acetobutylicum, the ratio of ExpCL/ExpC was considered to be crucial for the changes in the glycolysis process. Remarkably, the adaptive evolutionary enzyme 2-keto3-deoxy-6-phosphogluconate aldolase (CA_C2973) was observed to be significantly up-regulated in the presence of lignin in both exponential and stationary phases; this enzyme can reversibly catalyse KDPG to pyruvate and glyceraldehyde-3-phosphate, bypassing the entire glycolytic process without any ATP production [35-37]. This protein is a vital protein in the modified Entner-Doudoroff (ED) pathway found in Archaea and Clostridium aceticum growing in extreme conditions [38]. Microbes using different glucose catabolic pathways is a little known fact; however, it solely depends on species and

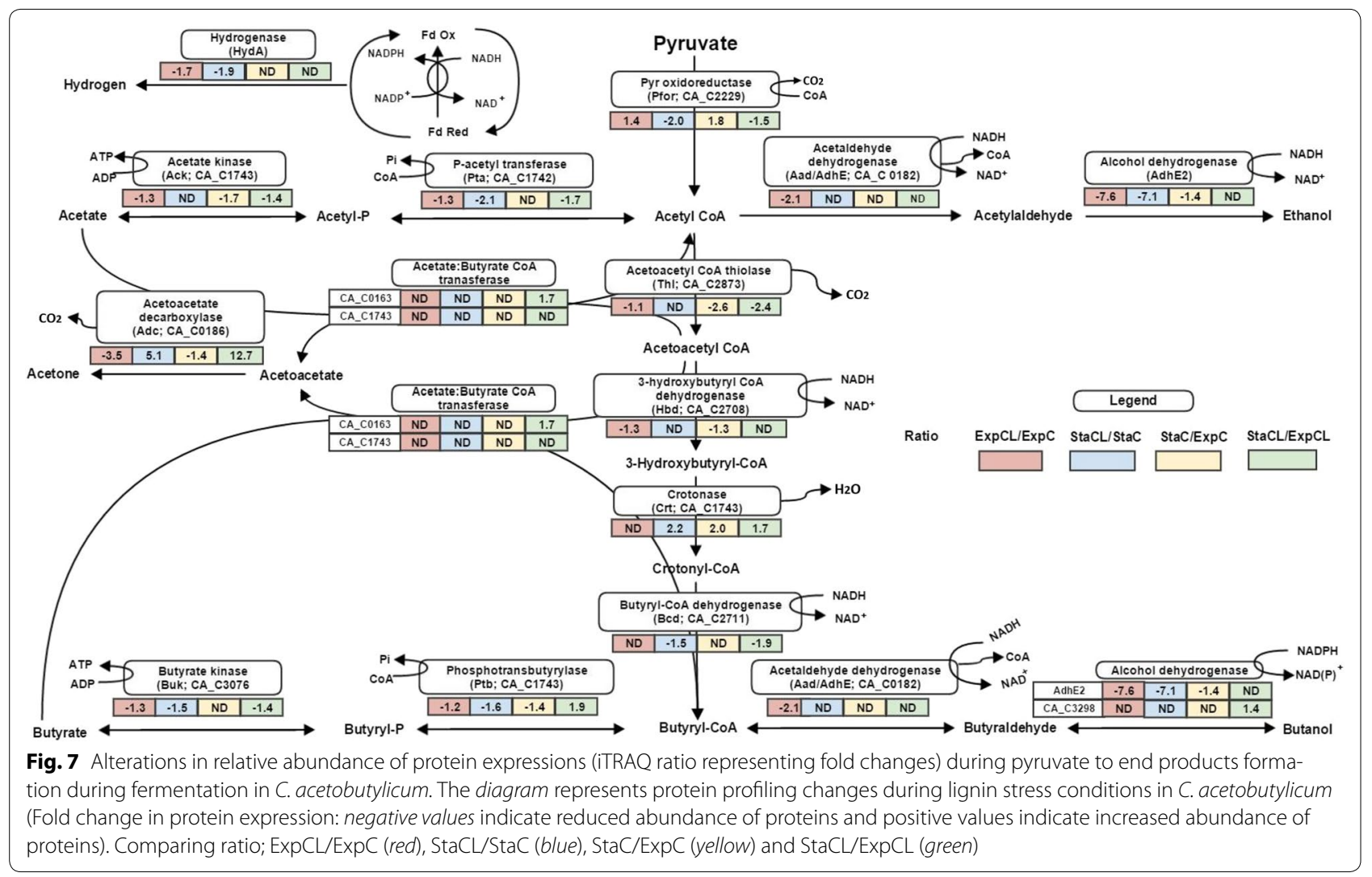


culture conditions [39]. Our results show that in presence of lignin, where EMP pathway proteins were downregulated, cells might have attempted to maintain the cellular pyruvate/acetyl CoA level to achieve normal metabolic functions. This protein skips crucial steps in glycolysis, resulting in no net ATP generation. Although enolase (CA_C0713) was identified in this study, no differential expression was found. Our data show a reduced abundance of phosphofructokinase (CA_C0517) and this was adaptively accompanied by a reverse reaction catalysed by protein fructose 1,6-biphosphatase (CA C1088), which had an elevated abundance in the lignin stress condition. Interestingly, tricarboxylic acid (TCA) cycle proteins aconitase (CA_C0971) and NAD-isocitrate dehydrogenase (CA_C0972) were up-regulated in the exponential phase of CL grown cells (ExpCL/ExpC). These proteins are involved in energy harvesting via $\mathrm{NADH} / \mathrm{NADPH}$ generation [40]. Therefore, it can be possible that to compensate for low NADH derived from glycolysis in the presence of lignin, the bacterium adaptively increased expression of these proteins.

\section{Protein expression changes associated with fermentation pathway regulation}

Clostridium acetobutylicum is a model organism for $\mathrm{ABE}$ fermentation. The enzymes involved in acid and solvent production pathways were identified in both conditions with differential expressions. In agreement with the negative effect of lignin on glycolysis, the subsequent fermentation pathways were also found to be down-regulated in CL conditions. The network of differentially expressed proteins during acidogenesis and solventogenesis is shown in Fig. 7.

The major route for the synthesis of fermentation products starts with pyruvate, which is first converted into acetyl CoA, carbon dioxide $\left(\mathrm{CO}_{2}\right)$ and reduced ferredoxin (or flavodoxin; Fld) [41]. This further undergoes a biphasic branched fermentation process, where acids (formic acid, acetic acid and butyric acid) are produced during acidogenesis and solvents (ethanol and butanol) are produced during solventogenesis [42, 43]. Reduced flavodoxin $(\mathrm{Rd})$ is further used as an electron carrier for either $\mathrm{NADH}, \mathrm{NAD}(\mathrm{P}) \mathrm{H}$ or hydrogen production depending on the cellular states [44]. In this study, we found increased acetic acid and hydrogen production, indicating carbon and electron flow towards the molecular hydrogen production and carbon flow towards acetic acid in both conditions. The hydrogenase ( $\mathrm{HydA})$ that receives electrons from flavodoxin (Fed) and produces hydrogen was only quantified by a single unique peptide at low abundance in CL conditions. Even though tentative, this observation is in agreement with lower hydrogen production in the CL condition (Fig. 3b). The enzymes involved in acetic acid and butyric acid production were down-regulated in lignin condition $(\mathrm{CL})$, particularly, acetate kinase $\left(\mathrm{CA}_{-}\right.$ C1743), phosphate acetyltransferase (CA_C1742), acetaldehyde dehydrogenase (CA_P0162), butyrate kinase (CA_C3075) and phosphate transbutyrylase (CA_C3076) (Fig. 7). However, no significant difference was observed in acids production in both conditions, but Fig. 3c, d indicates decreased acid production during the stationary phase of $\mathrm{C}$, this possibly explains the utilization of acids for solvent production (ethanol and butanol) was faster in C than CL conditions. This can be further justified by subsequent down-regulation of solvent-producing enzymes in CL: acetaldehyde dehydrogenase (CA_C0162) and (AdhE2) (ExpCL/ExpC and StaCL/ ExpC). Down-regulation of these enzymes suggests less conversion of acids into solvents in CL. This is in agreement with our metabolite analysis (Fig. 3e, f). Interestingly, the protein acetoacetate decarboxylase (CA_P0165) (involved in acetone production) was differentially regulated across all comparisons, but no acetone production was observed during fermentation. No expression of acetate/butyrate CoA transferase (CA_P0163, CA_P0164) was observed in both conditions, indicating that these enzymes possibly controlled acetone production in C. acetobutylicum. Providing evidence to this suggestion, it was previously found that acetone production was controlled at the transcriptional level through the expression of CoA transferase, but not through the expression of acetoacetate carboxylase [44, 45]. In addition, our results are in agreement with previous studies that suggested that higher hydrogen production results in less or no acetone production when $C$. acetobutylicum was grown on cellobiose as the substrate [23-25]. Some studies also found that higher hydrogen partial pressure resulted in lower acetone production $[27,46]$. As seen in our data, two major ATP generation pathways, i.e. glycolysis and acid production were down-regulated in lignin conditions, likely resulting in lower ATP production. This could be the possible reason for reduced abundance of those proteins that possess ATP-dependant activity with a consequent effect on various functions related to transcription/translation and in cell division/sporulation.

\section{Protein expression changes associated with DNA metabolism/transcription/translation}

Since C. acetobutylicum produces acids and solvents at different stages of its life cycle and lignin affects their production due to changes in metabolism as confirmed by GC and proteomic data, we decided to investigate other metabolic functions (e.g. DNA metabolism, transcription/translation) that may contribute to this behaviour and also correlated to changes in cell morphology. Fold changes in protein expression levels of various other 
metabolic functions during growth on $\mathrm{C}$ and $\mathrm{CL}$ are shown in Additional file 3: Fig. S1 and Table S1. These changes appear to manifest as an adaptive survival strategy of this bacterium at the replication, transcription and translation level [47]. The regulation of the most relevant proteins to lignin-induced changes is discussed in the following sections.

The proteins involved in DNA repair, maintenance and stabilization that were only found in CL (StaCL/ExpCL), including DNA-binding protein HU (CA_C3211), nucleoid-associated protein (CA_C0126), and single-stranded DNA-binding protein (CA_C2382). These proteins were up-regulated in the presence of lignin, suggesting that DNA damage was induced by lignin, thus the repair system worked efficiently.

We found that many transcriptional proteins were observed to be present in low abundance when comparing stationary phases to their respective exponential phases in $\mathrm{C}$ and $\mathrm{CL}$ conditions. However, the adaptive transcriptional regulator Lrp family protein (CA_C0977) [47] and GTP sensing transcriptional pleiotropic repressor CodY protein (CA_C1786) [48] were up-regulated in CL conditions (ExpCL/ExpC and StaCL/StaC). GTP binding CodY protein suppresses many genes of transition from exponential to the stationary/sporulation phase by binding to DNA $[48,49]$. Increased abundance of this protein in CL conditions may correlate with a delay in sporulation/defective cell division in $\mathrm{CL}$ conditions. In addition, the transcription regulatory septation protein SpoVG (CA_C3223) (involved in a site-specific DNAbinding activity) [50] was down-regulated in the presence of lignin and, therefore, cells may not have been able to control normal cell division and sporulation conditions, resulting in the filamentous morphology observed with CL grown cells.

We also identified 33 ribosomal proteins differentially regulated between the $\mathrm{CL}$ and $\mathrm{C}$ conditions. However, it was observed that during the exponential phase of CL conditions, most of the ribosomal proteins were increased in abundance $(\operatorname{ExpCL} / \operatorname{ExC})$. These proteins were also increased in abundance during stationary phases compared to their respective exponential phases (StaC/ExpC and StaCL/ExpCL). These proteins are normally down-regulated during stress conditions and stationary phases. The possible reason for increased abundance of these proteins could be correlated to the low expression of the ATP-dependent Lon protease (CA C2637), which degrades ribosomal proteins when cells starve for amino acids [51]. This effect could be possible, since a major translational regulator [52] protein TYPA/ BIPA ATPase (CA_C1684) was significantly downregulated in CL conditions. This protein alters ribosomal structure/function to achieve normal translation in
C. acetobutylicum. The activity of this protein has been shown to be GTP dependent and also previously correlated with adaptive response to stress [53]. The lower abundance of this protein possibly was dominated by high abundance of a suppressor CodY protein, since both require GTP for its activity.

When comparing the stationary phase of $\mathrm{C}$ and $\mathrm{CL}$ to their respective exponential phases (StaCL/ExpCL and $\mathrm{StaC} / \mathrm{ExpC}$ ), proteins such as 5-methylthioadenosine $S$-adenosylhomocysteine (SAM) nucleosidase (pfs CA_C2117) (salvage pathway) and M18 family aminopeptidase (apeA CA_C1091 and apeB CA_C0607) that recycle amino acids from peptides (preferably aspartate glutamate) were up-regulated during the stationary phase of both conditions. SAM nucleosidase (that produces universal quorum sensing autoinducer-2 [54]) was up-regulated during solventogenesis and may be the vital indicator of transition of phases [18].

This strongly suggests that metabolic activities are highly regulated at the transcription and translational level, not only in lignin conditions, but also during the transition from exponential to stationary phase.

\section{Protein expression changes associated with chemotaxis/ cell division/sporulation/energy metabolism}

Chemotaxis and motility are the vital functions in the lifestyle of many unicellular organisms and are metabolically costly processes. In this study, flagellin $(\mathrm{flaC})$ and chemotaxis proteins (CheW and CheA) (CA_C2224 and CA_C2220) that trigger cellular motility in response to environmental conditions were significantly down-regulated in CL (ExpCL/ExpC and StaCL/StaC). These results are consistent with the literature which demonstrated loss of motility associated with no solvent production in C. acetobutylicum [55-57]. Interestingly, ESAT-6 antigen-like protein (CA_C0040), a vital early expression protein of secretion system VII was found in significantly high abundance in CL conditions. This indicates a strong and early response to lignin, which could have vital role in chemotaxis activity via flagellin in C. acetobutylicum. We speculate that there must be relation between ESAT6. Chew/ChewA and flagellin that triggers the initial stress response with subsequent changes in transcription/translation sporulation/cell division proteins.

In this study, we identified seven differentially regulated proteins from the divisome (division complex). As C. acetobutylicum is closely related to $B$. subtilis, it can be speculated that the structural complex could be similar to the divisome in B. subtilis. Our data show most of these proteins were up-regulated during growth on $\mathrm{CL}$ compared to $\mathrm{C}$, indicating significant changes in divisomes (ExpCL/ExpC) induced by lignin. In particular, protein DivIVA (CA_C2118), a vital self-recruiting protein and 
involved in chromosome segregation during sporulation [58], SepF (CA_C2120), Z ring forming protein and cell division protein FtsX (CA_C0498) and FtsZ (CA_C1693) were found to be at increased abundance. In previous studies, high abundance of these proteins was correlated to abnormal morphology [59] and delay in sporulation [58]. This is confirmed by the controller of the sporulation protein (Spo0A) being down-regulated in $\mathrm{CL}$ conditions (ExpCL/ExpC and StaCL/StaC). Sporulation Spo0A (CA_C2071) induces the ftsZ protein to allow cells to divide at transcriptional level and governs sporulation/ solventogenesis at the transcriptional level $[60,61]$.

Evidence suggests that cell division and sporulation are concomitantly regulated by a stress response protein complex (ClpP, ClpX and $\mathrm{ClpC}$ and Lon protease) that works as a quality control and regulatory proteolysis pathway under stress conditions [62] to remove/stabilize defective or aggregated proteins. In this study, we found that several ATP-dependent proteins, ClpB (CA_C0959), ClpC (CA_C094, CA_C3189), DnaK (CA_C1282), Lon (CA_C2637), TerE (CA_C1412) and hsp18 (CA_C3714), were significantly down-regulated in lignin stress conditions. Therefore, we hypothesize that the quality control system of this bacterium fails to keep cells up to date, resulting in abnormal cell division/sporulation.

It has been demonstrated that the relative concentrations of nucleotides (particularly ATP and GTP) play important roles in cell physiology and regulation [63]. In C. acetobutylicum, glycolysis and acids production during the exponential phase are energy generation (ATP generation) steps [64]. In this work, seven subunits from ATP synthase were identified, including alpha, beta, gamma, epsilon and delta subunits. However, the relative abundance of these proteins was not significantly regulated in both conditions. This suggests that intracellular protons are mostly used for hydrogen production, thus limiting expenditure of ATP at substrate level phosphorylation [65]. Thus, it can be hypothesized that downregulation of glycolysis and acid production decreased ATP synthesis in CL conditions to cumulatively affect cell regulation. WrbA family protein (multimeric flavodoxin) (CA_C3314) was found at high abundance in CL treatment (StaCL/StaC and StaCL/ExpCL) which is involved in electron transfer systems and only expresses during adaptive cell response to stress conditions [66].

It has been proposed that $C$. acetobutylicum possesses another energy conserving module based on $\mathrm{NADH}$ :ferredoxin oxidoreductase (rnf) and butyryl-CoA dehydrogenase complex (Bcd/etfAB), [67] also proposed in Clostridium kluyveri [68]. Interestingly, we identified butyryl-CoA dehydrogenase (Bcd) (CA_C2711), electron transfer flavoprotein (subunit etfA (CA_C2709) and etfB (CA_C2710) and probable NADH/NADPH oxidoreductase (CA_C1958) in both conditions, suggesting the presence of extra energy conserving modules in this bacterium.

\section{Conclusions}

In conclusion, our study presents the most comprehensive analysis of the effect of lignin on cellular metabolism of C. acetobutylicum. This is the first time that the inhibitory effect of lignin on growth, morphology, $A B E$ and $\mathrm{H}_{2}$ production and cellular functions was investigated and integrated. Glycolysis, fermentation and associated pathways were significantly repressed when lignin was present. Several proteins involved in the glycolysis and fermentation pathways were down-regulated in the presence of lignin concomitantly with lower ATP production. Lignin also suppressed the ATP-dependent Clp protease complex (which controls normal cell division) synthesis and activity resulting in a delay in sporulation and solventogenesis. Lignin imposed morphological adaptation since cellular stress associated with decreased ATP-dependent housekeeping activity and the cellular divisome were affected. Our main aim was to analyse the 'lignin bottleneck' by monitoring fermentation end products and associated changes in the proteome of $C$. acetobutylicum in response to lignin with a view on providing insights into lignocellulose as a feedstock for biofuel generation. Our results shed light on the breadth of the metabolic routes involved in the lignin response in a commercially valuable bacterium for future implementation for lignocellulosic biofuel generation.

\section{Methods}

\section{Bacterial strain and growth conditions}

All chemicals and reagents were purchased from SigmaAldrich (Poole, UK) unless otherwise specified. C. acetobutylicum ATCC 824 was procured from the German Collection of Microorganisms and Cell Cultures (DSMZ, Braunschweig, Germany) and was maintained anaerobically on medium as previously described by LopezContreras et al. [69]. Briefly, the growth media contained $0.75 \mathrm{~g} \mathrm{~L}^{-1} \mathrm{KH}_{2} \mathrm{PO}_{4}, 0.75 \mathrm{~g} \mathrm{~L}^{-1} \mathrm{~K}_{2} \mathrm{HPO}_{4}, 0.348 \mathrm{~g} \mathrm{~L}^{-1}$ $\mathrm{MgSO}_{4}, 0.01 \mathrm{~g} \mathrm{~L}^{-1} \mathrm{MnSO}_{4} \cdot \mathrm{H}_{2} \mathrm{O}, 0.01 \mathrm{~g} \mathrm{~L}^{-1} \mathrm{FeSO}_{4} \cdot 7 \mathrm{H}_{2} \mathrm{O}$, $1 \mathrm{~g} \mathrm{~L}^{-1} \mathrm{NaCl}, 1.0 \mathrm{~g} \mathrm{~L}^{-1}$ cysteine chloride, $5 \mathrm{~g} \mathrm{~L}^{-1}$ yeast extract and $2 \mathrm{~g} \mathrm{~L}^{-1}\left(\mathrm{NH}_{4}\right)_{2} \mathrm{SO}_{4}$.

The cellobiose-only growth medium was prepared with $5 \mathrm{~g} \mathrm{~L}^{-1}$ cellobiose (hereafter denoted as C) whereas the cellobiose/lignin medium was prepared with $5 \mathrm{~g} \mathrm{~L}^{-1}$ cellobiose plus $1 \mathrm{~g} \mathrm{~L}^{-1} \mathrm{Kraft}$ lignin (alkali, carboxylated lignin; Sigma-Aldrich; Cat. No. 470996-100G) (hereafter denoted as $\mathrm{CL}$ ). Media were anaerobically prepared in the presence of $100 \%$ nitrogen gas in 125 - mL serum bottles and autoclaved. The culture media were seeded with $1 \mathrm{~mL}$ of 18-h-long cultures in which optical density (OD) 
at $600 \mathrm{~nm}$ was equal to 1.3. Cultures were incubated at $37{ }^{\circ} \mathrm{C}$ and growth curves were monitored at $\mathrm{OD}_{600 \mathrm{~nm}}$ using an UltraSpec 2100 (Amersham Bioscience, GE Healthcare, Buckinghamshire, UK). The cellobiose concentration was estimated by the Anthrone method [70].

\section{Microscopic observations}

Cell morphology was observed using Olympus microscope BX51 (Tokyo, Japan) fitted with a CapturePro 2.6-JENOPTIK Laser, Optik, System (GmbH, Germany) camera and an FEI Tecnai transmission electron microscope at an accelerating voltage of $80 \mathrm{kV}$. Electron micrographs were taken using a Gatan digital camera (Gatan, Oxon, UK).

\section{Fermentation end products analysis}

Targeted fermentation products were identified and quantified as previously reported by Pham et al. [71]. Briefly, ethanol, butanol, acetic acid and butyric acid were detected and quantified using an Agilent 7890A gas chromatograph (GC) (Cheshire, UK) instrument equipped with a flame ionization detector (FID) and Stabbilwax $(30 \mathrm{~m} \times 0.25 \mathrm{~mm}$ ID $\times 0.25 \mu \mathrm{m} \mathrm{df})$ fused silica column (Thames Restek, Buckinghamshire, UK). Aliquots $(50 \mu \mathrm{L})$ were collected from four biological replicates, centrifuged at $17,000 \times g$ for $2 \mathrm{~min}$ and transferred to a GC vial, and then $2 \mu \mathrm{L}$ of supernatant was injected into the column. The GC was controlled and automated by ChemStation (Agilent, Rev: 32.3.8) software. Each GC run was performed for $14 \mathrm{~min}$ using a temperature gradient (with a hold at $45^{\circ} \mathrm{C}$ for $3 \mathrm{~min}$, followed by a ramp at a rate of $15^{\circ} \mathrm{C} / \mathrm{min}$ to $120^{\circ} \mathrm{C}$, then $30^{\circ} \mathrm{C} / \mathrm{min}$ to $210^{\circ} \mathrm{C}$ and finally a hold $1 \mathrm{~min}$ at $210{ }^{\circ} \mathrm{C}$ ). Helium was used as the carrier gas at a flow rate of $20 \mathrm{~mL} \mathrm{~min}{ }^{-1}$. The injector, detector and oven temperatures were 250,350 and $120^{\circ} \mathrm{C}$, respectively. The concentrations of ethanol, butanol, acetic acid and butyric acid were estimated by comparing its retention time and peak area against standard curves of respective metabolite.

\section{Hydrogen gas estimation}

Gas samples from four biological replicates were collected from the headspace culture bottles using $10 \mathrm{~mL}$ gas tight syringes at different interval times. At each time point, the sample was injected into a gas chromatograph TRACE 1300 (Thermo Scientific, Paisley, UK) equipped with a thermal conductivity detector (TCD) and a $250 \mu \mathrm{L}$ of sample was injected into the column. Separation was achieved using a precolumn Haysep Q (60-80) column with $2 \mathrm{~m} \times 1 / 16$ SS packing connected with Molsieve 5 A (60-80) column with $2 \mathrm{~m} \times 1 / 16$ SS packing. Argon was used as carrier at 36.25 psi pressure. Each GC run was performed for 13 min using a temperature gradient (with a hold at $50{ }^{\circ} \mathrm{C}$ for $2.5 \mathrm{~min}$, followed by a ramp at a rate of $20{ }^{\circ} \mathrm{C} / \mathrm{min}$ to $70{ }^{\circ} \mathrm{C}$ for $45 \mathrm{~s}$, then hold at $70{ }^{\circ} \mathrm{C}$ for next $8.35 \mathrm{~min}$ and finally ramp of $1 \mathrm{~min}$ up to $150^{\circ} \mathrm{C}$ ). The detector and valve oven temperatures were 150 and $80{ }^{\circ} \mathrm{C}$, respectively. The GC was controlled and automated by the Chromeleon software (Dionex, Version 7). The instrument was calibrated using hydrogen gas standards of 10,30 and $40 \%(v / v)$ from BOC (Guildford, Surrey, UK).

\section{Cell harvesting and protein extraction}

Cells grown in C and CL media were harvested at midexponential $(16 \mathrm{~h})$ and late stationary $(48 \mathrm{~h})$ phases and pelleted by centrifugation at $10,000 \times g$ for 5 min at $4{ }^{\circ} \mathrm{C}$. Cell pellets were washed twice with phosphate buffer saline (PBS) and once with $0.5 \mathrm{M}$ triethylammonium bicarbonate (TEAB), pH 8.5 buffer. The cells were resuspended in $600 \mu \mathrm{L}$ lysis buffer [0.5 M TEAB containing $0.095 \%(v / v)$ sodium dodecyl sulphate (SDS) and $5 \mu \mathrm{L}$ protease inhibitor cocktail set II, pH 8.5] and $300 \mathrm{mg}$ sterilized acid-washed glass beads $(425-600 \mu \mathrm{m})$ were also added. Cell lysis was performed using a cell disruptor (Genie, VWR, UK) with 20 cycles of alternative $1 \mathrm{~min}$ vortexing and $1 \mathrm{~min}$ incubation on ice. Unbroken cells and cell debris were pelleted by centrifugation at $21,000 \times g$ for $90 \mathrm{~min}$ at $4{ }^{\circ} \mathrm{C}$ and the supernatant was transferred to a clean Eppendorf tube. Five microlitre of benzonase ${ }^{\circledR}$ nuclease (1:100) was added to the supernatant to clarify the sample by degradation of nucleic acids. Proteins were acetone precipitated (approximately $16 \mathrm{~h}$ ) at $-20{ }^{\circ} \mathrm{C}$ (ratio sample: acetone $=1: 4 \mathrm{v} / \mathrm{v}$ ). Precipitated proteins were recovered by centrifugation at $17,000 \times g$ for $20 \mathrm{~min}$ at $-9{ }^{\circ} \mathrm{C}$ and air dried. Finally, the pellet was dissolved in $0.5 \mathrm{M} \mathrm{TEAB}, \mathrm{pH} 8.5$ buffer containing $0.1 \%$ $(v / v)$ RapiGest SF (Waters, Milford, MA, USA). The total protein concentration was estimated by the Bradford assay according to the manufacturer's protocol.

\section{Quantitative workflow and iTRAQ labelling}

iTRAQ 8-plex labelling was performed for samples according to the manufacturer's protocol (8-plex iTRAQ reagent Multiplex kit, ABSciex, USA). Briefly, $100 \mu \mathrm{g}$ of proteins from each sample was first reduced with $1 \mu \mathrm{L}$ of $50 \mathrm{mM}$ Tris (2-carboxyethyl) phosphine hydrochloride and incubated at $60{ }^{\circ} \mathrm{C}$ for $1 \mathrm{~h}$. Samples were then alkylated using $1 \mu \mathrm{L}$ of $200 \mathrm{mM}$ methyl methanethiosulfonate at room temperature for $10 \mathrm{~min}$. Subsequently, proteins were digested with trypsin (Promega, UK) at a ratio of 1:50 (trypsin:protein) overnight at $37^{\circ} \mathrm{C}$. An independent biological duplicate was used for each phenotype. Each biological phenotype was labelled with relevant iTRAQ reagents as shown in Fig. 1. Labelled peptides were acidified with trifluoroacetic acid to 
precipitate RapiGest SF and removed by centrifugation at $17,000 \times g$ for $5 \mathrm{~min}$ at $4{ }^{\circ} \mathrm{C}$. iTRAQ-labelled peptides, present in the eight sample supernatants, were combined and concentrated by a vacuum concentration (Scanvac, Lynge, Denmark).

\section{Off-line fractionation}

iTRAQ-labelled peptides were off-line fractionated using hydrophilic interaction liquid chromatography (HILIC) on an Agilent 1100 HPLC (Berkshire, UK). Dried peptides were re-suspended in HILIC buffer A [80 \% $(v / v)$ acetonitrile (ACN), $10 \mathrm{mM}$ ammonium formate, $\mathrm{pH} 3$ ] and loaded to polyhydroxyethyl-A column, $5 \mu \mathrm{m}$ pore size, $100 \mathrm{~mm}$ length, $4.6 \mathrm{~mm}$ ID (Poly LC, MD, USA) at a flow rate of $0.5 \mathrm{~mL} / \mathrm{min}$ using an UVD170U detector (Dionex/LC packings, The Netherlands) at $280 \mathrm{~nm}$. HILIC buffer A and buffer B [5 \% $(v / v)$ ACN, $10 \mathrm{mM}$ ammonium formate, $\mathrm{pH}$ 5] were used to perform a 90 min gradient of $0 \%$ B for $10 \mathrm{~min}, 0-20 \%$ B for $15 \mathrm{~min}$, $20-40 \%$ for $30 \mathrm{~min}, 40-60 \%$ for $15 \mathrm{~min}, 60-100 \%$ B for $5 \mathrm{~min}$, and $100 \% \mathrm{~A}$ for $15 \mathrm{~min}$. Fractionation and chromatogram were monitored through Chromeleon software (Thermo, Hemel Hempstead, UK). Fifty-eight fractions were collected at one-minute intervals and dried by vacuum concentration (Scanvac, Lynge, Denmark) before tandem mass spectrometric analysis.

\section{Mass spectrometry analysis}

HILIC fractions were solubilised in reverse phase (RP) buffer A [3 $\%(v / v)$ acetonitrile, $0.1 \%(v / v)$ formic acid (FA)] before submitting to a QStarXL Hybrid ESI Quadrupole Time-of-Flight Tandem mass spectrometer [Applied Biosystems (now ABSciex), Famingham, MA] coupled with an online Ultimate 3000 HPLC system (Dionex, Surrey UK). Reverse-phase peptide separation was performed on a C18 Acclaim ${ }^{\circledR}$ PepMap100 column $(3 \mu \mathrm{m}, 100 \AA, 15 \mathrm{~cm})$ at a flow rate of $300 \mathrm{~nL} \mathrm{~min}^{-1}$. A 120-min linear gradient was applied; RP buffer A and RP buffer B [97 \% $(v / v)$ ACN, $0.1 \%(v / v)$ FA] were used as follows: 0-3 \% B for $5 \mathrm{~min}, 3-35 \%$ B for $90 \mathrm{~min}, 35-90 \%$ of B for $0.5 \mathrm{~min}, 90 \%$ of B for $6.5 \mathrm{~min}$, finally $3 \%$ of buffer $B$ for $18 \mathrm{~min}$. Data were acquired in positive ion mode in the data-dependent acquisition mode. The MS survey scan was set to cover the $m / z$ range of 350-1800 Th and the MS/MS survey scan was set to the $m / z$ range of 100 1600 Th using Analyst ${ }^{\circledR}$ QS 2.0 software (ABSciex, Famingham, MA). Peptides of charge $+2,+3,+4$ (intensity binning) for each TOF-MS scan $(400-1250 \mathrm{~m} / z)$ were dynamically selected and isolated for MS/MS fragment ion scans $(100-1600 \mathrm{~m} / z)$. Two RP-HPLC-MS runs per HILIC fraction were performed.

\section{Data interpretation and protein identification}

The generated tandem MS data files (.wiff) from the QSTAR XL were converted into mascot generic files (.mgf) via the mascot.dll embedded script (V1.6) coupled with Analyst QS v. 1.1.1 (ABSciex, MDS-Sciex). Peptide identification was performed using an in-house Phenyx algorithm cluster (Binary version 2.6, Genebio Geneva, Switzerland) using the $C$. acetobutylicum ATCC 824 database (taxon ID: 272562) containing 3825 protein sequences, which was downloaded from Uniprot (http://www.uniprot.org, June 2014). Searches were also conducted against a forward/reverse concatenated database to determine the false discovery rate (FDR). Search parameters considered trypsin as enzyme allowing a maximum of two missed cleavage sites. As fixed modifications, 8-plex iTRAQ of lysine $(\mathrm{K})$ and peptide $\mathrm{N}$-terminus $(+304 \mathrm{Th})$ and methylthio of cysteine residues $(+46 \mathrm{Th})$ were included in the search. Oxidation of methionine $(+16 \mathrm{Th})$ and deamidation $(\mathrm{N}$ and $\mathrm{Q})(-1$ $\mathrm{Th})$ were also considered as variable modifications. Mass tolerances for peptide identification were set to 0.5 and $0.2 \mathrm{Da}$ for MS and MS/MS, respectively. Thresholds for identified peptides were set to a minimal $Z$-score of 5.0, a $p$ value of $10^{-4}$, an AC score of 5 and peptide length of minimum six amino acids. Phenyx results were exported to Excel ".xls format and $1 \%$ FDR with two unique peptides per protein was used as the confident protein identifier. iTRAQ ratios used for relative quantification were determined by applying an in-house data analysis pipeline [72]. Isotopic and median corrections were applied to the reporter ion's intensities to compensate systematic errors between labels. Ultimately, a statistical method, described by Pham et al. [73] was applied to determine which proteins were significantly regulated at $p$ value $<0.05$. Cluster analysis and Principal Component Analysis were performed using Mathematica 10.2 software (Wolfram Research, Oxfordshire, UK).

\section{Additional files}

Additional file 1. Metabolites data. The detailed metabolites information included cellobiose consumption, cell dry biomass, acetic acid, butyric acid, ethanol, butanol and hydrogen gas are provided in separate excel file "Supporting information metabolites concentrations".

Additional file 2. Proteomic data. The detailed proteomics information included, Phenyx ID, quantification ID and fold changes (iTRAQ ratio; ExpCL vs ExpC, StaCL/StaC, StaC vs ExpC and StaCL vs ExpC) are provided in separate excel file "Supporting information proteomics iTRAQ".

Additional file 3: Fig. S1. Alterations in relative abundance of protein expressions (iTRAQ ratio representing fold changes) in other metabolic pathways during growth on $\mathrm{C}$ and $\mathrm{Cl}$. Table S1. Comparing protein regulations between C (control) and CL at exponential (Exp) and stationary (Sta) phases. Table includes identified proteins, fold change and $p$ value for each comparison. 


\begin{abstract}
Abbreviations
ABE: acetone-butanol-ethanol; iTRAQ: isobaric tags for relative and absolute quantitation; FDR: false discovery rate; C: cellobiose; CL: cellobiose plus lignin; $\mathrm{H}_{2}$ : molecular hydrogen; PCA: principal component analysis; PEP: phosphoenolpyruvate; PTS: phosphotransferase system; KDPG: 2-keto-3-deoxy6-phosphogluconate; EMP: Embden-Meyerhof-Parnas; ED: Entner-Doudoroff; GC: gas chromatography; TCA: tricarboxylic acid; HydA: hydrogenase; SAM: S-adenosylmethionine; OD: optical density; FID: flame ionization detector; TCD: thermal conductivity detector; PBS: phosphate buffer saline; TEAB: triethylammonium bicarbonate; SDS: sodium dodecyl sulphate; FA: formic acid; HILIC: hydrophilic interaction liquid chromatography; ACN: acetonitrile; HPLC: high-performance liquid chromatography; MS: mass spectrometry; RP: reverse phase.
\end{abstract}

\section{Authors' contributions}

MPR and PCW conceived and designed all experiments. MPR, NC and TKP participated in fermentation and proteomics experiments. MPR, TKP, NC, JN and CE helped with the data analysis. All authors participated in the draft writing and revision of the manuscript. All authors read and approved the final manuscript.

\section{Author details}

${ }^{1}$ The ChELSI Institute, Department of Chemical and Biological Engineering, University of Sheffield, Mappin Street, Sheffield S1 3JD, UK. ${ }^{2}$ Chaire de Bioinformatique, LGBA, Conservatoire National Des Arts Et Métiers, 75003 Paris, France. ${ }^{3}$ Present Address: School of Chemical Engineering and Advanced Materials, Faculty of Science, Agriculture \& Engineering, Newcastle University, Newcastle upon Tyne NE1 7RU, UK.

\section{Acknowledgements}

No other acknowledgements here other than funding, which we describe above.

\section{Availability of supporting data}

The online version of this article contains supplementary material, which is available to authorized users.

\section{Competing interests}

The authors declare that they have no competing interests.

\section{Consent for publication}

All the authors consent to publish this research work.

\section{Ethical approval and consent to publish}

Not applicable.

\section{Funding}

The funding bodies played no direct role in any aspect of the research reported here other than providing funding that allowed the research to be done. We acknowledge funding from The Ministry of Social Justice and Empowerment, Government of India (National Overseas Fellowship; Grant No. 11015/22/2008-SCD-V), the SUNLIBB project (Sustainable Liquid Biofuels from Biomass Biorefining - project 251132, FP7-ENERGY-2009-BRAZIL) and the EPSRC (EP/I031812/1 and EP/E036252/1).

Received: 26 October 2015 Accepted: 9 May 2016

Published online: 31 May 2016

\section{References}

1. Brethauer S, Studer MH. Consolidated bioprocessing of lignocellulose by a microbial consortium. Energy Environ Sci. 2014;7:1446-53.

2. Ezeji T, Qureshi N, Blaschek HP. Butanol production from agricultural residues: impact of degradation products on Clostridium beijerinckii growth and butanol fermentation. Biotechnol Bioeng. 2007;97:1460-9.

3. Sabathe F, Soucaille P. Characterization of the CipA scaffolding protein and in vivo production of a minicellulosome in Clostridium acetobutylicum. J Bacteriol. 2003;185:1092-6.
4. Cappelletti BM, Reginatto V, Amante ER, Antonio RV. Fermentative production of hydrogen from cassava processing wastewater by Clostridium acetobutylicum. Renew Energy. 2011;36:3367-72.

5. Zhu J, Pan X. Woody biomass pretreatment for cellulosic ethanol production: technology and energy consumption evaluation. Bioresour Technol. 2010;101:4992-5002.

6. Pan X, Arato C, Gilkes N, Gregg D, Mabee W, Pye K. Biorefining of softwoods using ethanol organosolv pulping: preliminary evaluation of process streams for manufacture of fuel-grade ethanol and co-products. Biotechnol Bioeng. 2005;90:473-81.

7. Baral NR, Shah A. Microbial inhibitors: formation and effects on acetonebutanol-ethanol fermentation of lignocellulosic biomass. Appl Microbiol Biotechnol. 2014;98:9151-72.

8. Sun Z, Liu S. Production of $n$-butanol from concentrated sugar maple hemicellulosic hydrolysate by Clostridium acetobutylicum ATCC 824. Biomass Bioenerg. 2012;39:39-47.

9. Gomez LD, Vanholme R, Bird S, Goeminne G, Trindade LM, Polikarpov I, Simister R, Morreel K, Boerjan W, McQueen-Mason SJ. Side by side comparison of chemical compounds generated by aqueous pretreatments of maize stover, Miscanthus and sugarcane bagasse. Bioenerg Res. 2014;7:1466-80.

10. Janshekar H, Brown C, Haltmeier Th, Leisola M, Fiechter A. Bioalteration of kraft pine lignin by Phanerochaete chrysosporium. Arch Microbiol. 1982;132:14-21.

11. Perestelo F, Falcon MA, Perez ML, Roig EC, de la Fuente MG. Bioalteration of kraft pine lignin by Bacillus megaterium isolated from compost piles. J Ferment Bioeng. 1989;80:151-3.

12. Morii H, Nakamiya K, Kinoshita S. Isolation of lignin-decolorizing bacterium. J Ferment Bioeng. 1995;80:296-9.

13. Chen $Y H$, Chai LY, Zhu YH, Yang ZH, Zheng Y, Zhang $H$. Biodegradation of kraft lignin by a bacterial strain Comamonas sp. B-9 isolated from eroded bamboo slips. J Appl Microbiol. 2012;112(5):900-6.

14. Wei Z, Zeng G, Huang F, Kosa M, Huang D, Ragauskas AJ. Bioconversion of oxygen-pretreated Kraft lignin to microbial lipid with oleaginous Rhodococcus opacus DSM 1069. Green Chem. 2015;17:2784-9.

15. Zhao C, Xie S, Pu Y, Zhang R, Huang F, Ragauskas AJ, Yuan JS. Synergistic enzymatic and microbial lignin conversion. Green Chem. 2016. doi:10.1039/c5gc01955a.

16. Zhao Y, Tomas CA, Rudolph FB, Papoutsakis ET, Bennett GN. Intracellular butyryl phosphate and acetyl phosphate concentrations in Clostridium acetobutylicum and their implications for solvent formation. Appl Environ Microbiol. 2005;71:530-7.

17. Justice SS, Hunstad DA, Cegelski L, Hultgren SJ. Morphological plasticity as a bacterial survival strategy. Nat Rev Microbiol. 2008;6:162-8.

18. Steiner E, Scott J, Minton NP, Winzer K. An agr quorum sensing system that regulates granulose formation and sporulation in Clostridium acetobutylicum. Appl Environ Microbiol. 2012;78:1113-22.

19. Mutschlechner O, Swoboda H, Gapes J. Continuous two-stage ABEfermentation using Clostridium beijerinckii NRRL B 592 operating with a growth rate in the first stage vessel close to its maximal value. J Mol Microbiol Biotechnol. 2000;2:101-5.

20. Jones DT, Woods DR. Acetone-butanol fermentation revisited. Microbiol Rev. 1986;50:484

21. Klein M, Ansorge-Schumacher MB, Fritsch M, Hartmeier W. Influence of hydrogenase overexpression on hydrogen production of Clostridium acetobutylicum DSM 792. Enzym Microb Tech. 2010;46:384-90.

22. Levin DB, Pitt L, Love M. Biohydrogen production: prospects and limitations to practical application. Int J Hydrog Energy. 2004;29:173-85.

23. Ren Z, Ward T, Logan B, Regan J. Characterization of the cellulolytic and hydrogen-producing activities of six mesophilic Clostridium species. J Appl Microbiol. 2007;103:2258-66.

24. Zhang H, Bruns MA, Logan BE. Biological hydrogen production by Clostridium acetobutylicum in an unsaturated flow reactor. Water Res. 2006;40:728-34.

25. Ramachandran U, Wrana N, Cicek N, Sparling R, Levin DB. Isolation and characterization of a hydrogen-and ethanol-producing Clostridium sp. strain URNW. Can J Microbiol. 2011;57:236-43.

26. Kumar M, Saini S, Gayen K. Elementary mode analysis reveals that Clostridium acetobutylicum modulates its metabolic strategy under external stress. Mol BioSyst. 2014;10:2090-105. 
27. Kim BH, Zeikus JG. Hydrogen metabolism in Clostridium acetobutylicum fermentation. J Microbiol Biotechnol. 1992;2:248-54.

28. Tashiro Y, Sonomoto K. Advances in butanol production by clostridia. In: Méndez-Vilas A, editor. Current research, technology and education topics in applied microbiology and microbial biotechnology; 2010. p. 1383-94.

29. Elias JE, Gygi SP. Target-decoy search strategy for increased confidence in large-scale protein identifications by mass spectrometry. Nat Methods. 2007:4:207-14.

30. Alsaker KV, Papoutsakis ET. Transcriptional program of early sporulation and stationary-phase events in Clostridium acetobutylicum. J Bacteriol. 2005;187:7103-18.

31. Jones SW, Paredes CJ, Tracy B, Cheng N, Sillers R, Senger RS. The transcriptional program underlying the physiology of clostridial sporulation. Genome Biol. 2008;9:R114

32. Tomas CA, Beamish J, Papoutsakis ET. Transcriptional analysis of butanol stress and tolerance in Clostridium acetobutylicum. J Bacteriol. 2004;186:2006-18.

33. Venkataramanan KP, Min L, Hou S, Jones SW, Ralston MT, Lee KH. Complex and extensive post-transcriptional regulation revealed by integrative proteomic and transcriptomic analysis of metabolite stress response in Clostridium acetobutylicum. Biotechnol Biofuels. 2015:8:1-29.

34. Servinsky MD, Kiel JT, Dupuy NF, Sund CJ. Transcriptional analysis of differential carbohydrate utilization by Clostridium acetobutylicum. Microbiology. 2010;156:3478-91.

35. Conway T. The Entner-Doudoroff pathway: history, physiology and molecular biology. FEMS Microbiol Rev. 1992;103:1-28.

36. Ahmed H, Tjaden B, Hensel R, Siebers B. Embden-Meyerhof-Parnas and Entner-Doudoroff pathways in Thermoproteus tenax: metabolic parallelism or specific adaptation? Biochem Soc Trans. 2004;32:303-4.

37. Kim S, Lee S. Identification and characterization of Sulfolobus solfataricus D-gluconate dehydratase: a key enzyme in the non-phosphorylated Entner-Doudoroff pathway. Biochem J. 2005:387:271-80.

38. Andreesen J, Gottschalk G. The occurrence of a modified EntnerDoudoroff pathway in Clostridium aceticum. Arch Microbiol. 1969;69:160-70.

39. Liu T, Zhu L, Wei W, Zhou Z. Function of glucose catabolic pathways in hydrogen production from glucose in Rhodobacter sphaeroides 6016. Int J Hydrog Energy. 2014;39:4215-21.

40. Hansford RG. Dehydrogenase activation by $\mathrm{Ca} 2+$ in cells and tissues. J Bioenerg Biomembr. 1991;23:823-54.

41. Petitdemange H, Cherrier C, Bengone J, Gay R. Study of the NADH and $\mathrm{NADPH}$-ferredoxin oxidoreductase activities in Clostridium acetobutylicum. Can J Microbiol. 1977:23:152-60.

42. Lee SY, Park JH, Jang SH, Nielsen LK, Kim J, Jung KS. Fermentative butanol production by Clostridia. Biotechnol Bioeng. 2008:101:209-28.

43. Durre P. Formation of solvents in clostridia. In: Handbook on clostridia. 2005; p. 671-85.

44. Husemann MH, Papoutsakis ET. Enzymes limiting butanol and acetone formation in continuous and batch cultures of Clostridium acetobutylicum. Appl Microbiol Biotechnol. 1989:31:435-44.

45. Vasconcelos I, Girbal L, Soucaille P. Regulation of carbon and electron flow in Clostridium acetobutylicum grown in chemostat culture at neutral pH on mixtures of glucose and glycerol. J Bacteriol. 1994;176:1443-50.

46. Yerushalmi L, Volesky B, Szczesny T. Effect of increased hydrogen partial pressure on the acetone-butanol fermentation by Clostridium acetobutylicum. Appl Microbiol Biotechnol. 1985:22:103-7.

47. Peeters $E$, Charlier D. The Lrp family of transcription regulators in archaea. Archaea. 2010;750457:2010

48. Ratnayake-Lecamwasam M, Serror P, Wong K-W, Sonenshein AL. Bacillus subtilis CodY represses early-stationary-phase genes by sensing GTP levels. Genes Dev. 2001;15:1093-103.

49. Serror $\mathrm{P}$, Sonenshein AL. CodY is required for nutritional repression of Bacillus subtilis genetic competence. J Bacteriol. 1996;178:5910-5.

50. Jutras BL, Chenail AM, Rowland CL, Carroll D, Miller MC, Bykowski T. Eubacterial SpoVG homologs constitute a new family of site-specific DNA-binding proteins. PLoS One. 2013;8:e66683.

51. Dalebroux ZD, Swanson MS. ppGpp: magic beyond RNA polymerase. Nat Rev Microbiol. 2012;10:203-12.
52. Krishnan K, Flower AM. Suppression of $\triangle$ bipA phenotypes in Escherichia coli by abolishment of pseudouridylation at specific sites on the $23 \mathrm{~S}$ rRNA. J Bacteriol. 2008;190:7675-83.

53. Kiss $E$, Huguet $T$, Poinsot $V$, Batut J. The typA gene is required for stress adaptation as well as for symbiosis of Sinorhizobium meliloti 1021 with certain Medicago truncatula lines. Mol Plant Microbe Interact. 2004;17:235-44.

54. Parveen N, Cornell KA. Methylthioadenosine/S-adenosylhomocysteine nucleosidase, a critical enzyme for bacterial metabolism. Mol Microbiol. $2011 ; 79: 7-20$

55. Sivagnanam K, Raghavan V, Shah M, Hettich RL, Verberkmoes NC, Lefsrud MG. Comparative shotgun proteomic analysis of Clostridium acetobutylicum from butanol fermentation using glucose and xylose. Proteome Sci. 2011;9:66.

56. Petersen DJ, Bennett GN. Enzymatic characterization of a nonmotile, nonsolventogenic Clostridium acetobutylicum ATCC 824 mutant. Current Microbiol. 1991;23:253-8

57. Lyristis M, Boynton ZL, Petersen D, Kan Z, Bennett GN, Rudolph FB. Cloning, sequencing, and characterization of the gene encoding flagellin, flaC, and the post-translational modification of flagellin, FlaC, from Clostridium acetobutylicum ATCC824. Anaerobe. 2000;6:69-79.

58. Thomaides HB, Freeman M, El Karoui M, Errington J. Division site selection protein DivIVA of Bacillus subtilis has a second distinct function in chromosome segregation during sporulation. Genes Dev. 2001;15:1662-73.

59. Cha J-H, Stewart GC. The divIVA minicell locus of Bacillus subtilis. J Bacteriol. 1997;179:1671-83.

60. Harris LM, Welker NE, Papoutsakis ET. Northern, morphological, and fermentation analysis of spo0A inactivation and overexpression in Clostridium acetobutylicum ATCC 824. J Bacteriol. 2002;184:3586-97.

61. Burbulys D, Trach KA, Hoch JA. Initiation of sporulation in B. subtilis is controlled by a multicomponent phosphorelay. Cell. 1991:64:545-52.

62. Krüger E, Witt E, Ohlmeier S, Hanschke R, Hecker M. The Clp proteases of Bacillus subtilis are directly involved in degradation of misfolded proteins. J Bacteriol. 2000;182:3259-65.

63. Buckstein MH, He J, Rubin H. Characterization of nucleotide pools as a function of physiological state in Escherichia coli. J Bacteriol. 2008; 190:718-26.

64. Jabbari S, Steiner E, Heap JT, Winzer K, Minton NP, King JR. The putative influence of the agr operon upon survival mechanisms used by Clostridium acetobutylicum. Math Biosci. 2013;243:223-39.

65. Girbal L, Vasconcelos I, Soucaille P. Transmembrane pH of Clostridium acetobutylicum is inverted (more acidic inside) when the in vivo activity of hydrogenase is decreased. J Bacteriol. 1994;176:6146-7.

66. Carey J, Brynda J, Wolfová J, Grandori R, Gustavsson T, Ettrich R. WrbA bridges bacterial flavodoxins and eukaryotic NAD (P) H: quinone oxidoreductases. Protein Sci. 2007:16:2301-5.

67. Boynton ZL, Bennet G, Rudolph FB. Cloning, sequencing, and expression of clustered genes encoding beta-hydroxybutyryl-coenzyme A (CoA) dehydrogenase, crotonase, and butyryl-CoA dehydrogenase from Clostridium acetobutylicum ATCC 824. J Bacteriol. 1996;178:3015-24.

68. Seedorf H, Fricke WF, Veith B, Bruggemann H, Liesegang H, Strittmatter A. The genome of Clostridium kluyveri, a strict anaerobe with unique metabolic features. Proc Natl Acad Sci. 2008:105:2128-33.

69. López-Contreras AM, Martens AA, Szijarto N, Mooibroek H, Claassen PA, van der Oost J. Production by Clostridium acetobutylicum ATCC 824 of CelG, a cellulosomal glycoside hydrolase belonging to family 9. Appl Environ Microbiol. 2003:69:869-77.

70. Hedge J, Hofreiter B. Methods of estimating starch and carbohydrate. Carbohydr Chem. 1962;17:163-201.

71. Pham TK, Chong PK, Gan CS, Wright PC. Proteomic analysis of Saccharomyces cerevisiae under high gravity fermentation conditions. J Proteome Res. 2006:5:3411-9.

72. OW SY, Salim M, Noirel J, Evans C, Rehman I, Wright PC. iTRAQ underestimation in simple and complex mixtures: "the good, the bad and the ugly". J Proteome Res. 2009;8:5347-55.

73. Pham TK, Roy S, Noirel J, Douglas I, Wright PC, Stafford GP. A quantitative proteomic analysis of biofilm adaptation by the periodontal pathogen Tannerella forsythia. Proteomics. 2010;10:3130-41. 